\title{
Considerations for the Development of an Undergraduate Curriculum in Geriatric Medicine
}

\author{
K. Singler ${ }^{a, b} \quad$ C.C. Sieber ${ }^{a, b} \quad$ R. Biber ${ }^{a} \quad$ R.E. Roller \\ ${ }^{a}$ Institute for Biomedicine of Aging, Friedrich-Alexander University, and ${ }^{b}$ Department of Geriatrics, Klinikum \\ Nürnberg, Nürnberg, Germany; ' Department of Geriatrics and Curriculum Development, Medical University of Graz, \\ Department of Internal Medicine, Graz, Austria
}

\section{Key Words}

Medical education - Geriatrics · Curriculum development .

Learning objectives $\cdot$ Educational strategies

\begin{abstract}
Background: Although the number of older patients is increasing in almost all medical specialties, the interest of medical students in geriatrics as a career is still low. Because quality of medical education and educators strongly influences student career decisions, it is important to develop curricula that motivate students to become self-directed, lifelong learners in the field of geriatric medicine. Objectives: We evaluated training aspects in terms of time, core content of teaching goals, and quality of undergraduate geriatric education in medical schools in Austria and Germany. Methods: A standardized paper questionnaire was sent to all 36 German and 4 Austrian medical faculties to evaluate quantitative aspects, content, and quality of pregraduate medical education in geriatrics. Results were compared to the recommendations of the Geriatric Medicine Section of the European Union of Medical Specialists (UEMS). Results: A total of 33/36 (92 of the German medical faculties) and 4/4 (100 of the Austrian medical faculties) responded to the questionnaire. In most of the faculties, geriatric medicine was taught as an independent discipline in the core curriculum, with learning objectives absent in almost one third of
\end{abstract}

the faculties. A medical student's first contact with geriatric medicine occurred on average during the second clinical year (median 8th semester). Although the content of geriatric curricula strongly varied among the faculties, core knowledge as recommended by the UEMS was integrated into most of the curricula. Teaching strategies regarding the development of attitudes and skills also recommended by the UEMS were identified in the curriculum of only some faculties. Conclusions: Geriatrics seems to be an established subject in most German and Austrian faculties. However, the current data clearly indicate highly variable quality in geriatric pregraduate training at German and Austrian universities. Because curricula should prepare young people using competence-based training and assessment methods, room for improvement remains not only in terms of structure, but also regarding quality of training to develop self-directed lifelong learners.

Copyright $\odot 2013$ S. Karger AG, Basel

\section{Introduction}

\section{Geriatric Needs in Europe}

The 'greying Western hemisphere' provides a basis for numerous economic and political agendas, and older and multimorbid people are the main consumers within the ambulatory and institutionalized health care systems [1].

\section{KARGER}

E-Mail karger@karger.com

www.karger.com/ger
(C) 2013 S. Karger AG, Basel

0304-324X/13/0595-0385\$38.00/0
Katrin Singler, MD

Institute for Biomedicine of Aging, Friedrich-Alexander University

Heimerichstrasse 58

DE-90419 Nürnberg (Germany)

E-Mail Katrin.Singler@klinikum-nuernberg.de 
Nevertheless, awareness of the need for adaptation is low. General practitioners, usually not trained for the special needs of multimorbid and older clients, generally provide primary care [2]. However, the number of such patients is increasing not only in primary care, but also in all medical specialties. Despite these facts, geriatric medicine as a medical subspecialty is still not attractive for most doctors in Europe.

One of the main reasons is the missing geriatric content within pregraduate medical training at medical universities. As the literature indicates, the attitude of medical students towards older patients and their care is very heterogeneous, and the interest in geriatric medicine as a medical career is low [3-5]. Furthermore, the quality of medical education and its teachers strongly influences career decisions [6]. Therefore, geriatric content needs to be implemented into medical core curricula. These developments have already been undertaken in the UK $[7,8]$. High quality of both, training methods and educators is essential to give geriatric medicine the perspectives required as a result of demographic changes.

The current analysis is performed using the 'six-step approach for curricular development in medical education' published by Kern et al. [9]. As the general needs assessment is confirmed by the current demographic shift and the need for changes within health care systems, our objective was an evaluation of undergraduate teaching in geriatrics in order to identify needs within Germanspeaking universities. Beside the amount of the geriatricrelated content in medical curricula in Germany and Austria the authors also intended to address the quality of training provided.

\section{Methods}

\section{Study Design - Questionnaire - Procedure}

We conducted a survey about the concepts of undergraduate student training. All medical universities in Germany and Austria were included. Similar to recent educational surveys in the UK [8], we used a structured paper questionnaire to evaluate training aspects in terms of time, core content of the teaching goals and quality of undergraduate geriatric education in medical schools of the two countries. The questionnaire was developed as part of the current study and piloted in four faculties in September/October 2011; any ambiguous questions were subsequently refined. The questionnaire consisted of 14 closed (mostly multiple choice) questions and one open question, grouped as follows: general questions about geriatric-related content in the core curriculum, aspects with a focus on aims and learning objectives, and questions with regard to training format and methods of knowledge assessment. The timing of a student's first encounter with geriatric medicine in the curriculum was also elucidated. The validity of indi- vidual data collection was controlled by repeated hidden content within different questions. At the end of the questionnaire, an open question provided the chance for individual feedback.

In September 2011, the blinded paper questionnaire was sent to the deans of all 36 German medical faculties and 4 Austrian medical universities with a request to forward it to the person responsible for the curriculum of undergraduate geriatric medical education or to nominate a person, who would have an overview of geriatric education as delivered to the students. At 3 and 6 months, a reminder was sent to the faculties that had not yet responded. Data collection was closed on May 1, 2012. Two independent experienced medical teachers double checked the data from the returned questionnaires, and data analysis was performed using SPSS version 16.0 for Windows (SPSS Inc., Chicago, Ill., USA). Continuous variables are presented as medians (interquartile range; IQR) and categorical variables as numbers and percentages. Fisher's exact test was used to detect significant frequency differences of categorical variables. $p \leq 0.05$ was considered statistically significant.

For medical faculties with a modular system without semesters or that divided the academic year into three teaching periods (trimesters), data were converted into the equivalent year at a medical school. To obtain quality ranking of the results, geriatric core content and training methods were compared to the European recommendations for undergraduate training in geriatric medicine currently provided by the UEMS [10].

The ethical committees of the Friedrich-Alexander University Erlangen-Nürnberg and the Medical University of Graz approved the study.

\section{Results}

The response rate to the questionnaire was 33/36 (92 in Germany) and 4/4 (100 in Austria). Sex was equally distributed among the respondents (table 1). The median general teaching experience of those answering the questionnaire and therefore officially appointed teachers responsible for the geriatric curriculum was 15 years (IQR 10-20); for specified teaching experience in geriatric medicine, it was 6 years (IQR 5-8).

In nearly all German and half of the Austrian faculties responding to the questionnaire, geriatric medicine was taught as an independent discipline within the core curriculum ( 97 vs. 50 ). The first contact medical students had with geriatric medicine was during clinical training (median within the 4 th year of training), independent of the structure of the whole curriculum (longitudinal or modular curriculum). Only six medical faculties (two with modular and four faculties with longitudinal curricula) introduced geriatric medicine within the first 2 years of pregraduate training (fig. 1).

Despite the fact that $57 \%(21 / 37)$ of all medical faculties provided a written curriculum for medical education in geriatrics, detailed written learning objectives and 
Table 1. Comparison of curricular content, learning strategies, assessment methods and training if teachers between German and Austrian faculties (percent values)

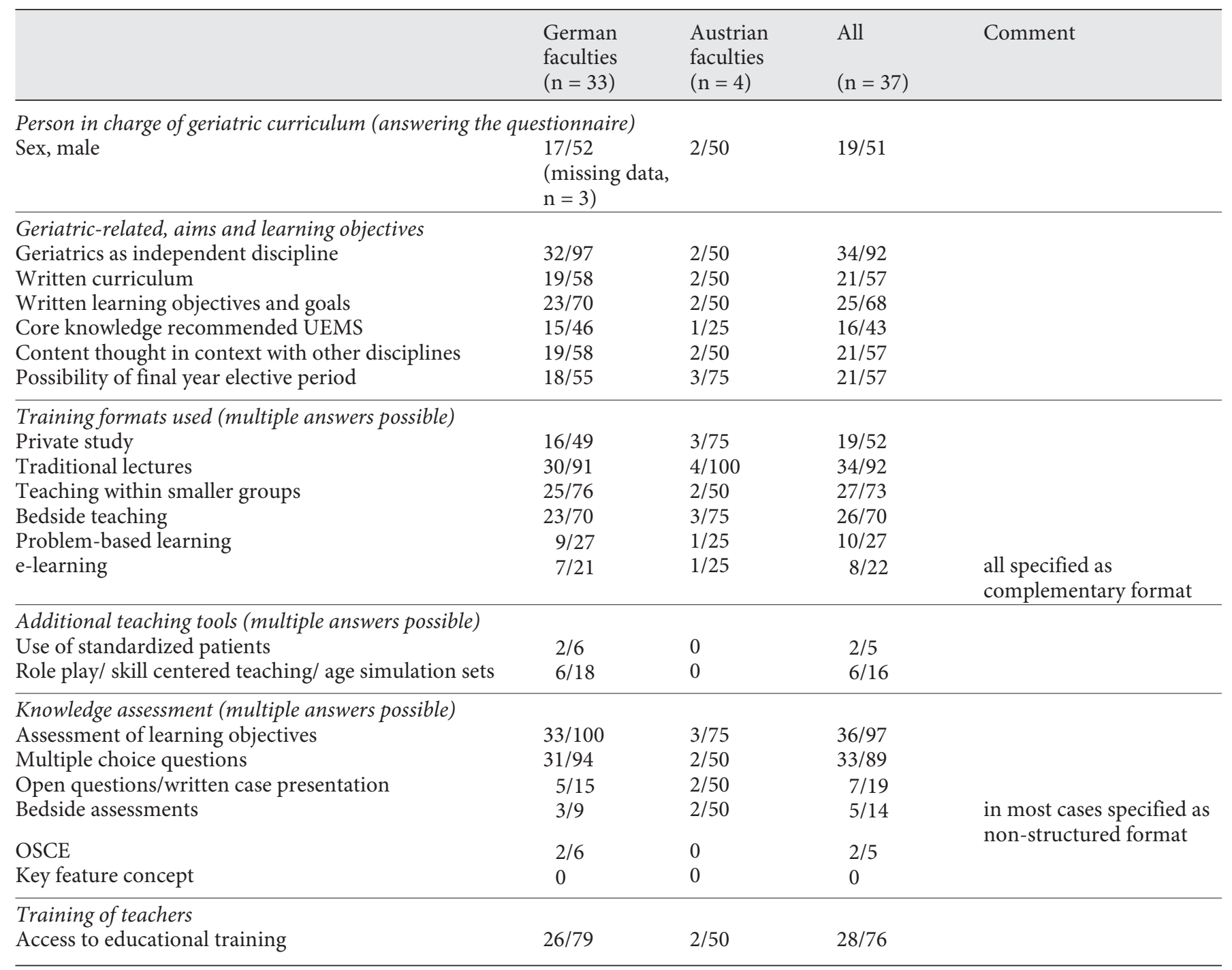

goals for geriatric medicine were present in nearly $70 \%$ $(n=23)$ of the German and 50\% $(n=2)$ of the Austrian medical faculties. The content of the geriatric curricula varied considerably within the participating faculties (table 2). Core competencies as defined and recommended by the Union European Medicine Society-Geriatric Medicine Section (UEMS-GMS) were taught at 15 (46 of the German and one of the four Austrian faculties). At 19 (58 of the German) and 2 (50 of the Austrian) faculties, geriatric content was partly taught in context with other clinical disciplines or basic sciences.

In more than $50 \%$ of the German and $2 / 3$ of the Austrian faculties, geriatrics was offered as an option for an elective period during the final clinical year ( 55 vs. 75 ) either as an elective period in internal medicine or as a special training integrated into the elective period in internal medicine.

The participants of the survey were asked to list all teaching strategies used in geriatric teaching at their universities, and multiple answers were possible (table 1). The most commonly used teaching strategies at German and Austrian faculties were traditional lectures (91 vs. $100)$ followed by small group teaching sessions, such as journal clubs or tutorials at German faculties (76) and private studies as well as bedside teaching at Austrian faculties. Clinical teaching in the ward was also at place three 


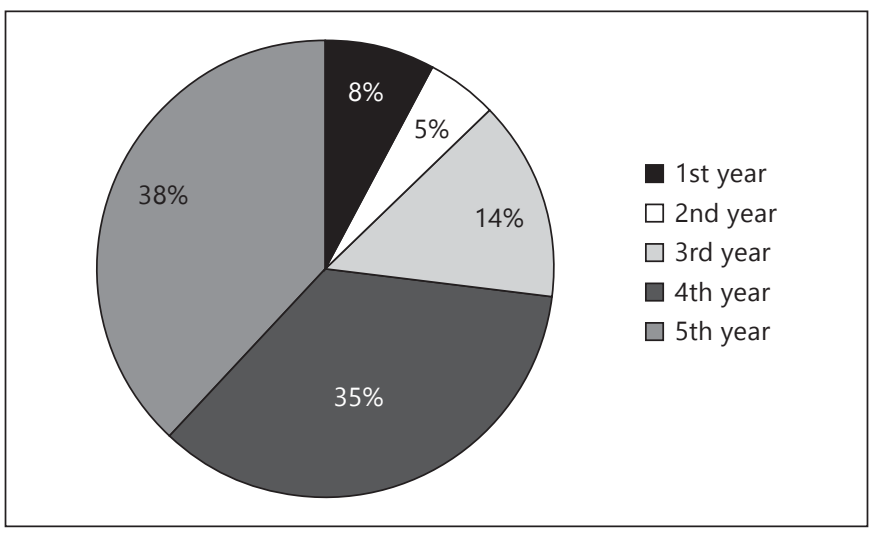

Fig. 1. Year of undergraduate medical training with students' first contact with geriatric medicine.

Table 2. Contents of geriatric curricula in Germany and Austria

\begin{tabular}{llc}
\hline Content & $\begin{array}{l}\text { Number of faculties } \\
\text { that include the topic } \\
\text { in their curriculum } \\
\text { (n=37) }\end{array}$ \\
\cline { 2 - 3 } & $\mathrm{n}$ & $\%$ \\
\hline Demographics/epidemiology & 35 & 94.6 \\
Physiology und pathophysiology of aging & 29 & 78.4 \\
Comprehensive geriatric assessment & 35 & 94.6 \\
The geriatric team & 24 & 64.9 \\
Prevention in old patients & 22 & 59.5 \\
Polypharmacy in old patients & 33 & 89.2 \\
Cognitive and behavioral dysfunction & 36 & 97.3 \\
Mobility and gait disorders, falls & 33 & 89.2 \\
Pain in the elderly & 29 & 78.4 \\
Nutrition & 28 & 75.7 \\
Incontinence & 29 & 78.4 \\
Ethical problems in the old & 26 & 70.3 \\
Dementia and secondary diseases & 36 & 97.3 \\
Rehabilitation & 30 & 81.1 \\
Palliative geriatric care & 28 & 75.7 \\
Communication skills & 15 & 40.5 \\
Legal foundations by communicating with & & \\
$\quad$ old patients & 21 & 56.8 \\
\hline
\end{tabular}

Content at single universities: Frailty, chronic wounds, geriatric oncology, parkinsonism, sexuality, agism, orthogeriatrics, multimorbidity, sociomedical aspects, evidence-based medicine, differential diagnoses.

of the most commonly used teaching strategies at German faculties. Only a minority of the faculties of both countries used problem-based learning and electronic educational tools (E-Learning) as complementary teaching strategies. Skills and attitudes, for instance, by the use of age simulation sets or role plays were taught at six German faculties. Only two German faculties had already implemented standardized patients in geriatric training. The data showed a median use of 3 (IQR 2-4.5) different educational strategies at German and Austrian faculties.

All German and 2/3 of the Austrian faculties tested the individually acquired knowledge and competences using regularly performed assessments. Of those faculties performing an assessment, $67 \%$ of the Austrian but only $21 \%$ (7/33) of the German faculties used varying assessment methods to address different educational levels according to Miller's pyramid of competence [11]. Miller's approach allows to depict four different levels of competence (knows, knows how, shows how, does) and helps to define skills, performance and competence-based assessment. Nearly all German and 2 of the Austrian faculties used multiple choice question assessments in varying formats (94 vs. 50$) .15 \%(n=5)$ of the German and $50 \%$ of the Austrian faculties used a written examination with open questions or written case presentations. Also $50 \%$ of the Austrian faculties, but only 9\% (3/33) of the German faculties performed bedside assessments, but at nearly all of these faculties bedside assessment was performed in nonstructured formats. Both Austrian faculties as well as two German faculties combined bedside assessment with a written assessment (multiple choice or open questions). At one German faculty, geriatric knowledge and competences were only assessed by bedside assessment, using a structured format. Only two German faculties examined their students via objective structured clinical examination (OSCE), and none of the faculties used a key feature concept. In the responses no difference was made between different modes of examination (summative or formative) or if the written examination was paper or computer based. No association was found between the use of learning objectives and the use of different assessment methods ( $\mathrm{p}=0.34$ ).

Another focus was on educator training. Only roughly $80 \%$ of the German and half of the Austrian faculties provided access to educational training opportunities on a regular basis to their teachers. Looking at the number of teachers specialized in geriatric medicine, big differences were seen among the individual faculties. The percentage varied from $\leq 10 \%$ at 6 German and 2 Austrian faculties to $\geq 90 \%$ at 8 of the German and 1 of the Austrian faculties (median Germany 65\% (IQR 16-91.3), Austria 50\% (IQR 0-87.5)) (fig. 2). Nongeriatric disciplines involved in geriatric education varied tremendously between the single faculties and ranged from trauma surgeons to dermatologists, ophthalmologists. 


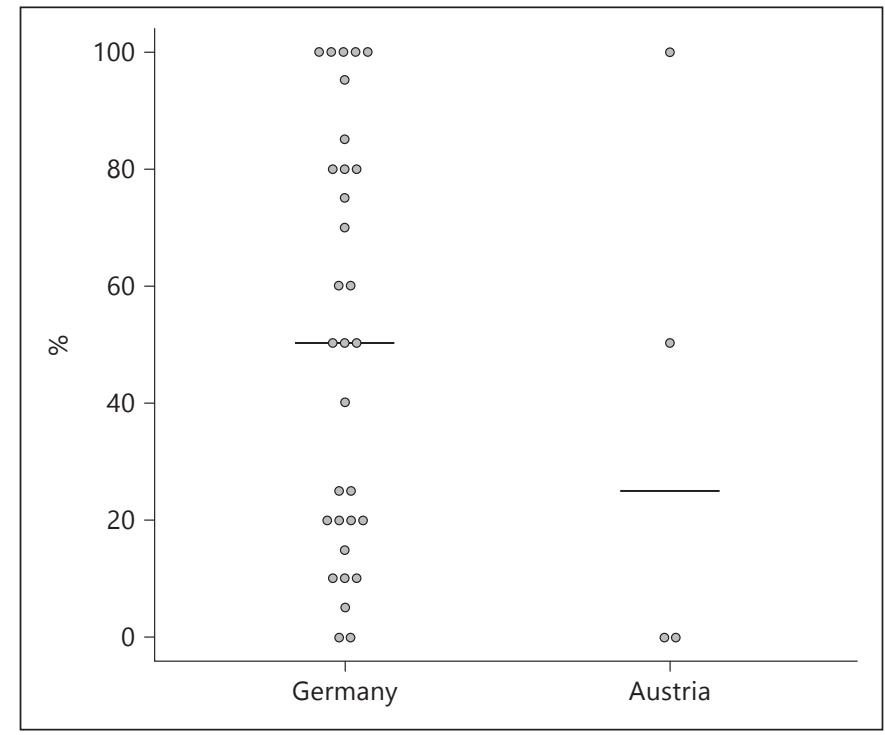

Fig. 2. Percentage of geriatricians in geriatric pregraduate training.

Data on the median load of teaching assignments for one teacher were lacking in general. From the data provided by the faculties $(26 / 37)$, the median teaching load was two contact hours per teacher during one teaching period (semester or trimester).

Only 14 of all 37 faculties answered to the free question regarding expectations for further curricular development in geriatric medicine. As to the format given, multiple answers were possible. In a post hoc analysis, the retrievedanswerscouldbeclusteredinto thefollowingthree categories: augmentation of financial resources $(n=5)$, augmentation of human resources $(n=5)$, and extension of the spectrum of geriatric education $(n=6)$.

\section{Discussion}

The current study provides quantitative and qualitative information about undergraduate training in geriatric medicine in medical schools in Germany and Austria. Furthermore, training content and methods in geriatric medicine were evaluated in the light of preexisting European and national recommendations [10].

The general response rate to the questionnaire was amazingly high: $92 \%$ of German and $100 \%$ of Austrian medical faculties returned the evaluation form. Except for one faculty, all questionnaires distributed were answered by persons officially appointed and in charge of geriatric education at the faculties [8]. In that context, it is notable that the median teaching experience of the respondents who had been appointed by their faculties to organize the pregraduate geriatric training of all students was rather low, namely 6 years. However, the results retrieved from the official representatives of the faculties and presented here are feasible for drawing reliable conclusions about German and Austrian pregraduate training in geriatric medicine.

In a survey published by Kolb [12] in 2006, shortly after the implementation of the new German medical licensure act, geriatrics was present in only $67 \%$ of the medical faculties. Six years thereafter, geriatric medicine is taught as an independent specialty during the core curriculum in $97 \%$ of the German and $50 \%$ of the Austrian faculties. Thus, at first sight, geriatrics seems to be an established specialty in most of the universities, and almost all students seem to encounter geriatric teaching content during their time at medical school.

The initial contact typically occurs quite late during medical training, however only at four medical faculties with modular structure and two faculties with longitudinal curricula students were involved in geriatric medical education during their first 2 years at medical school. Otherwise, the first contact with geriatrics occurred during advanced medical training (median 4 th year). These facts are in disagreement with the European recommendations published by UEMS, which argues for an integral pregraduate geriatric curriculum starting in the basic sciences and progressing through to clinical teaching [10].

Many, but not all of the topics in geriatric medicine taught at German and Austrian universities meet the core knowledge recommended by the UEMS. The training of skills and attitudes are addressed less well within the curricula. The current standards of geriatric training at numerous Austrian and German universities do not reflect the European recommendations.

Written competence-based learning objectives are the basis for a distinct, competence driven curriculum, for effective learning methods and for assessment methods $[13,14]$.In fact, competence-based performancestandards have already been incorporated into a few medical curricula (e.g. in the UK) [15]. General dissemination is still rare elsewhere in Europe. As a matter of fact, there are no national German/Austrian or European competencebased performance standards in pregraduate training.

Geriatric medicine is based on teamwork, solving complex problems with highly developed skills, and fostering personal attitudes. Training methods of choice for these learning objectives are problem-based teaching strategies [16]. Also 'role plays', recommended for the medium of 
affective and psychomotor learning objectives, have already been used and studied in geriatric education [17, 18]. Our survey showed clearly that knowledge-based cognitive objectives (lectures) as well as attitudinal objectives (discussion rounds) were applied most frequently. Modern teaching methods that match psychomotor objectives (skills, competences) and cognitive objectives such as problem-solving teaching strategies were restricted to individual faculties. Bedside teaching, as a very important part in clinical teaching, was still sparsely used in geriatric medical education ( $30 \%$ of the faculties). Therefore, training methods still do not reflect the competence levels, which should be addressed within geriatric medicine training at German and Austrian faculties.

The same seems to hold true for assessment methods used. Our data show no relationship ( $\mathrm{p}=0.34)$ between the use of competence-based assessment methods and the existence of defined learning objectives. This might have different explanations: One might be the lack of competence-based learning objectives, which lay the groundwork for an appropriate assessment of competences. The other is 'missing knowledge' about the educational impact of assessment methods. A multistation OSCE is most appropriate to objectively assess complex problems in patients suffering from multimorbidity [19]. Only two faculties use OSCE as an assessment in geriatrics. Mini-Cex testing or $360^{\circ}$ assessment would widen the spectrum also to behavioral skills and student attitudes towards patients and the whole working team [20-22]. None of these assessments were answered positively in the questionnaires. The 'hype of written examinations' may also just reflect missing financial and human resources within the faculties, which is clearly reflected by the open answers at the end of the questionnaire.

According to the recommendations of the UEMS, geriatric medical education 'must be planned, organized and monitored by experts in old age medicine' [10]. Medicine of aging is a cross-sectional subject and, at first sight, it seems to be feasible that a 'geriatric curriculum' is not only delivered exclusively by geriatricians. However, if geriatric medicine is intended to become a specialty within human medicine itself, geriatric core competences need to be taught by 'core competent geriatricians'.

\section{Conclusions and Further Perspectives}

Medical doctors meet older people in almost all specialties during their daily routine work. Medical universities and faculties have the duty to provide sustainable ed- ucation and prepare students for their future professional lives. Nowadays, geriatrics seems to be a widely established specialty in many medical universities; however, training standards vary broadly, and learning objectives and structured curricula are still lacking in many medical schools. Local stakeholders still seem to neglect the need for integrated and high-stake curricula in geriatrics. Nevertheless, knowledge and performance in the field are expected at the time of graduation.

Curricula must balance efficiency-thoughtful provision of modern teaching methods and assessments and prepare young people for their later professional lives. In that context, geriatric medicine has to become a basic standard in all medical universities and faculties across Europe. Medical students should encounter such training early during their education to acquire competencies necessary for the care of older patients. They should expand on these competencies throughout medical school and become self-directed lifelong learners. Well-trained and ambitious learners and future doctors will be the basis for growing the future of geriatric medicine. The current data clearly show the great variety in quality of training in geriatrics, at least at German-speaking universities. There is still room for improvement in terms of structure and quality of training.

\section{Acknowledgement}

This work received no financial support.

We thank R.J. Schulz (president, German Society of Geriatrics) and A. Möltner (Center of Excellence for Assessment in Medicine, University of Heidelberg) for their support.

\section{Disclosure Statement}

The authors declare that they have no conflict of interest.

\section{References}

1 Chambers GR (ed): Health Care Systems in the EU: A Comparative Study [Internet] European Parliament, Directorate General for Research; saco 101 en; 1998 [cited 26.06.2012] available at: http://www.europarl.europa.eu/ workingpapers/saco/pdf/101_en.pdf.

2 Goins RT, Gainor SJ, Pollard C, Spencer SM: Geriatric knowledge and educational needs among rural health care professionals. Gerontology 2003;29:261-272.

3 Coccaro EF, Miles AM: The attitudinal impact of training in gerontology/geriatrics in medical school: a review of the literature and perspective. J Am Geriatr Soc 1984;32:762-768. 
4 Perrotta P, Perkins D, Schimpfhauser F, Calkins E: Medical students' attitudes toward geriatric medicine and patients. J Med Educ 1981;56:478-483.

5 Fitzgerald JT, Wray LA, Halter JB, Williams BC, Supiano MA: Relating medical students' knowledge, attitudes, and experience to an interest in geriatric medicine. Gerontologist 2003;43:849-855

6 Bland KI, Isaacs G: Contemporary trends in student selection of medical specialties: the potential impact on general surgery. Arch Surg 2002;137:259-267.

7 Bartram L, Crome P, McGrath A, Corrado OJ, Allen SC, Crome I: Survey of training in geriatric medicine in UK undergraduate medical schools. Age Aging 2006;35:533-535.

8 Gordon AL, Blundell AG, Gladman JR, Masud T: Are we teaching our students what they need to know about ageing? Results from the UK National Survey of Undergraduate Teaching in Ageing and Geriatric Medicine. Age Ageing 2010;39:385-388.

9 Kern DE, Thomas PA, Hughes MT: Curriculum Development for Medical Education: A Six Step Approach, ed 2. Baltimore, John Hopkins University Press, 2009.

10 Geriatric section of the Union Européenne des médecines spécialistes (UEMS) [Internet] Undergraduate training; 2003 [cited 06.04.2012] available at http://www.uemsgeriatricmedicine.org/.
11 Miller GE: The assessment of clinical skills/ competence/performance. Acad Med 1990; 65:63-67.

12 Kolb G: Unterricht Q7 (Medizin des Alterns und des alten Menschen) an 36 deutschen medizinischen Fakultäten: Anschriften, Stunden-Zahlen, Unterrichtsorganisation. Euro J Ger 2006;8:236-245.

13 Anderson LW, Krathwohl DR, editors: A Taxonomy for Learning, Teaching and Assessing: A Revision of Bloom's Taxonomy of Educational Objectives. New York, Longman, 2001.

14 Bloom BS: Taxonomy of Educational Objectives: A Classification of Educational Objectives. Handbook 1: Cognitive Domain. New York, Longman, 1984.

15 British Geriatrics Society: The Medical Undergraduate Curriculum in Geriatric Medicine. Best Practice Guide 5.1 (revised July 2007) [cited 15.09.2012]. Available at http:// www.bgs.org.uk.
16 von Renteln-Kruse W, Dieckmann P, Anders J, Rösler A, Krause T, van den Bussche $\mathrm{H}$ : Medicine in old age and in the elderly. Educational concepts in area Q7 of the accreditation requirements and its first evaluation by students. Z Gerontol Geriatr 2005;38:288-292.

17 Alfarah Z, Schünemann HJ, Akl EA: Educational games in geriatric medicine education: a systematic review. BMC Geriatr 2010;10:19.

18 Pacala JT, Boult C, Hepburn K: Ten years' experience conducting the Aging Game workshop: was it worth it? J Am Geriatr Soc 2006; 54:144-149.

19 Karani R, Leipzig RM, Callahan EH, Thomas DC: An unfolding case with a linked Objective Structures Clinical Examination (OSCE): a curriculum in inpatient geriatric medicine. J Am Geriatr Soc 2004;52:1191-1198.

20 Norcini JJ, Blank LL, Duffy FD, Fortna GS: The mini-CEX: a method for assessing clinical skills. Ann Intern Med 2003;138:476-481.

21 Hauer KE: Enhancing feedback to students using the mini-CEX (Clinical Evaluation Exercise). Acad Med 2000;75:524.

22 Joshi R, Ling FW, Jaeger J: Assessment of a 360-degree instrument to evaluate residents' competency in interpersonal and communication skills. Acad Med 2004;79:458-463. 